\title{
A Study to Compare the Effectiveness of Sensorimotor Training and Balance Exercise in Subjects with Neck Pain
}

\author{
V. Rajalaxmi ${ }^{1}$, K. Varalakshmi ${ }^{2}$, S. Meena ${ }^{3}$, I. Deepa ${ }^{3}$, C. Ishwarya ${ }^{3}$, S. Latha ${ }^{4}$ \\ ${ }^{1}$ Professor, Faculty of Physiotherapy, Dr. M.G.R. Educational \& Research Institute University, Velappanchavadi, \\ Chennai - 600 077, Tamil Nadu, India, ${ }^{2}$ Internee, Faculty of Physiotherapy, Dr. M.G.R. Educational \& Research \\ Institute University, Velappanchavadi, Chennai - 600 077, Tamil Nadu, India, ${ }^{3}$ Assistant Professor,Faculty of \\ Physiotherapy, Dr. M.G.R. Educational \& Research Institute University, Velappanchavadi, Chennai - 600077, \\ Tamil Nadu, India, ${ }^{4}$ Research assistant, Faculty of Physiotherapy, Mahatma Gandhi medical college, Puducherry
}

\begin{abstract}
Aim: To compare the effectiveness of sensori-motor training and balance exercise in subjects with neck pain.

Background: Impaired cervical joint position sense, sensorimotor and balance are associated with neck pain. The presence of cervical musculoskeletal impairement was not specific to cervicogenic headache but was present in various recurrent headache types.

Methodology: This study was a comparative study design with pre and post type, 50 samples were selected based on the inclusion criteria. Group A received balance exercise and Group B received sensorimotor training. Both groups received exercises for $40 \mathrm{mins} / \mathrm{session}$ per day for 5 days a week for 12 weeks. Pre and post test measures taken using visual analogue scale, Ammer dizziness diagnostic scale, patient specific functional scale, Tinitee balance scale.
\end{abstract}

Result: On comparing the mean value of group A and group B on values, it shows significant difference between group A and group B. Group A Seems to be more effective than Group B.

Keywords: Neck pain, balance exercises, Sensorimotor.

\section{Introduction}

The neck pain is a common musculoskeletal disorder and a costly public health issue. The pain is often persistent or recurrent in nature. The underlying mechanisms for recurrence or persistence remain unclear but could be associated with altered proprioception from

\section{Corresponding Author:}

\section{Rajalaxmi}

Vice Principal, Faculty of Physiotherapy, Dr.

M.G.R. Educational \& Research Institute University, Velappanchavadi, Chennai - 600 077, Tamil Nadu, India.

Mobile Number: 9176123939

e-mail: rajalxmi.physio@drmrgdu.ac.in the neck muscles. Some patients usually have impaired proprioception and postural instability which account for these symptoms and the impairments can lead to decreased physical performance and increased concerns of falling, particularly the elderly. Dizziness and unsteadiness have been shown to be predictors of both poorer recovery and poorer response to musculoskeletal treatment. Thus it is important to address such symptoms and disturbances in patient with neck pain not only to gain symptomatic relief but also it reverse the impairment to improve physical performance and function ${ }^{1}$.In people with neck pain, coordination of head movements, intersegment coordination of the vertebrae of the cervical spine, and postural balance were show to be impaired ${ }^{2}$.There is an abundance of receptors in the cervical muscles, and there are multiple cervical central and reflex connections to the vestibular, visual, and 
postural control systems ${ }^{3}$. In particular, the deep portions of the suboccipital muscles have the highest cervical receptor density and are known to have a specific role in these reflex and central connections. ${ }^{4}$

It is estimated that between $10-40 \%$ of persons sustaining neck trauma as a result of a motor vehicle crush will go on to have chronic persistent problems. After pain, dizziness and unsteadiness are the next most frequent complaints in those with persistent problems following a whiplash trauma, with up to $70 \%$ reporting this complaints. ${ }^{5}$.

Cervicogenic dizziness is often related to upper cervical degeneration or a neck injury, such as whiplash. It is thought to result from a perturbation in sensory information from the upper cervical spine ${ }^{6}$. Neck pain has been shown to be associated with balance disturbances and gait speed are also known to decline with ageing. ${ }^{7}$ Neck pain is related to impaired postural balance among patients and is highly prevalent among workers with high postural demands. ${ }^{8}$ Dysfunction of the cervical receptors in neck disorders can alter afferent input subsequently changing the integration timing and tuning of sensorimotor control. ${ }^{9}$

Disturbances of balance have been found both in patients with whiplash associated disorders and idiopathic neck pain, neck pain precipitated by trauma resulted in greater or different balance impairments. ${ }^{10}$ Impaired cervical joint position sense is commonly argued to rely on abnormal cervical input if true muscle vibration, alternating afferent input, but not in mental interventions should have an effect on head repositioning acuity and neck pain perception. ${ }^{11}$ The role of deep cervical flexor muscles in postural support and the knowledge of impaired activation of these muscles in people with neck pain ${ }^{12}$. The deep portions of the sub occipital muscles have the highest cervical receptor density and are known to have a specific role in these reflex and central connections ${ }^{13}$. We found that greater and lesser dysfunction likewise was not related to headache classification or length of headache history. A chance in the nature of headache with age plays an important role in the choice of treatment. ${ }^{14}$
Reduced cervical range of motion is one of the main complaints from patients showing cervical dysfunction and seeking help from therapists ${ }^{15}$. The persistence of nonspecific neck pain may have a significant impact on patients with health status, activity of daily living, and work-related activities resulting in poor quality of life. ${ }^{16}$ Cervical afferent information is important to the control of posture, spatial orientation and coordination of the eyes and head ${ }^{17}$

Sensorimotor training emphasizes postural control and progressive challenges to the sensorimotor system to restore normal motor programmes in patient with neck pain. The balance training can effectively improve cervical sensorimotor function and decrease neck pain intensity.

\section{Material and Method}

This comparative study was conducted in the physiotherapy department took nearly 3 months to complete the study (January 2019-April 2019).50 samples were selected from 70 volunteers based on inclusion criteria of age group of 45 to 65 , insidious neck pain for at least 3 months and headache associated with neck pain, able to follow the instructions and spondylolysthesis and the excluded those with previous history of neck and head trauma or surgery, known vestibular pathology, vertigo or dizziness from ear to brain disorders, sensory nerve pathways. Inflammatory joint disease, cerebellar dysfunction. Both the group received exercise for $40 \mathrm{mins} / \mathrm{session}$ for 5 days a week for 12 weeks the pre and post-test measurement will be taken before and after 3 months by using VAS, patient specific functional scale, Ammer dizziness diagnostic scale, Tinetti balance scale. Group A received balance exercises and group B received sensory motor training.

Data Analysis: The collected data were tabulated and analyzed using both descriptive and inferential statistics. All the parameters were assessed using statistical package for social science (SPSS) version 20.0. Paired t-test was adopted to find statistical difference within the groups \& Independent t-test (Student t-Test) was adopted to find statistical difference between the groups. 
Table -1: Comparing The Values Of Vas Between Group-A And Group-B In Pre And Post Test Vluaes Using Independent (Student) $\mathrm{t}$-Test

\begin{tabular}{|l|c|c|c|c|c|c|c|c|c|}
\hline \multirow{2}{*}{ VAS } & \multicolumn{2}{|c|}{ Group A } & \multicolumn{2}{|c|}{ Group B } & \multirow{2}{*}{ t - Test } & \multirow{2}{*}{ Df } & \multicolumn{2}{|c|}{ 95\% CI of the difference } & \multirow{2}{*}{ SIG (2-tailed) } \\
\cline { 2 - 6 } & Mean & S.D & Mean & S.D & & & Lower & Upper & \\
\hline Pre Test & 7.12 & 0.66 & 7.2 & 0.67 & -0.842 & 24 & -0.54 & 0.22 & $0.404^{*}$ \\
\hline Post Test & 5.0 & 0.73 & 5.40 & 0.86 & 0.176 & 24 & -0.41 & 0.49 & $0.861^{* *}$ \\
\hline
\end{tabular}

Table -2: Comparing The Values Of Psfs Between Group-A And Group-B In Pre And Post Test Vluaes Using Independent (Student) $t$-Test

\begin{tabular}{|c|c|c|c|c|c|c|c|c|c|}
\hline \multirow{2}{*}{ PSFS } & \multicolumn{2}{|c|}{ Group A } & \multicolumn{2}{|c|}{ Group B } & \multirow{2}{*}{ t-Test } & \multirow{2}{*}{ Df } & \multicolumn{2}{|c|}{$95 \%$ CI of the difference } & \multirow{2}{*}{$\begin{array}{c}\text { SIG } \\
\text { (2-tailed) }\end{array}$} \\
\hline & Mean & S.D & Mean & S.D & & & Lower & Upper & \\
\hline Pre Test & 21.28 & 1.45 & 21.36 & 1.89 & -0.168 & 48 & -1.04 & 0.88 & $0.868^{*}$ \\
\hline Post Test & 15.28 & 1.44 & 16.08 & 2.63 & 1.331 & 48 & -0.40 & 2.0 & $0.190 * *$ \\
\hline
\end{tabular}

Table - 3: Comparing The Values Of Adds Between Group-A And Group-B In Pre And Post Test Vluaes Using Independent (Student) $\mathrm{t}$-Test

\begin{tabular}{|c|c|c|c|c|c|c|c|c|c|}
\hline \multirow{2}{*}{ ADDS } & \multicolumn{2}{|c|}{ Group A } & \multicolumn{2}{|c|}{ Group B } & \multirow{2}{*}{$\mathrm{t}$ - TEST } & \multirow{2}{*}{ Df } & \multicolumn{2}{|c|}{$95 \%$ CI of the difference } & \multirow{2}{*}{ SIG (2-tailed) } \\
\hline & Mean & S.D & Mean & S.D & & & Lower & Upper & \\
\hline Pre Test & 56.48 & 15.1 & 57.08 & 17.95 & -0.128 & 48 & -10.03 & 8.83 & $0.899^{*}$ \\
\hline Post Test & 31.9 & 6.7 & 33.04 & 6.54 & -0.594 & 48 & -4.91 & 2.67 & $0.555^{* *}$ \\
\hline
\end{tabular}

Table -4: Comparing The Values Of Tbs Between Group-A And Group-B In Pre And Post Test Vluaes Using Independent (Student) $\mathrm{t}$-Test

\begin{tabular}{|c|c|c|c|c|c|c|c|c|c|}
\hline \multirow{2}{*}{ TBS } & \multicolumn{2}{|c|}{ Group A } & \multicolumn{2}{|c|}{ Group B } & \multirow{2}{*}{ t-Test } & \multirow{2}{*}{ Df } & \multicolumn{2}{|c|}{$95 \%$ CI of the difference } & \multirow{2}{*}{ SIG (2-tailed) } \\
\hline & Mean & S.D & Mean & S.D & & & Lower & Upper & \\
\hline Pre Test & 6.5 & 1.98 & 6.2 & 1.82 & 0.594 & 48 & -0.76 & 1.40 & $0.555^{*}$ \\
\hline Post Test & 12.6 & 1.24 & 12.1 & 1.15 & -1.294 & 48 & -1.12 & 0.24 & $0.202 * *$ \\
\hline
\end{tabular}

\section{Results}

On comparing the mean values of VAS, both the groups have showed improvement in the post test mean values although the group-A post test mean value (5.0) showing lesser mean value is more effective than Group-B post test mean value (5.40).

On comparing the mean of PSFS, both the groups showed increased PSFS in the post test mean values. But the Group A post test mean value (16.08) showing the higher mean value is more effective than Group B post test mean value (15.28). On comparing the mean of ADDS, both the groups showed increased ADDS in the post test mean values. But the Group A post test mean value (31.09) showing the higher mean value is more effective than Group B post test mean value (33.04).

On comparing the mean of TBS, both the groups showed increased TBS in the post test mean values. But the Group A post test mean value (12.6) showing the higher mean value is more effective than Group B post test mean value (12.1).

\section{Discussion}

The present study was conducted with the sample size of 50 subjects to find out the efficacy of sensorimotor and balance exercise in subjects with neck pain. The present data indicates that balance exercise were indeed 
efficient in reducing the neck pain, dizziness and in improving the functional activities of the subjects.

In a previous study by Revel et al, evaluated slow motion proprioceptive exercise which mainly concerned with eye-neck coordination for 8 weeks resulted in reduction in neck pain significantly when compared to other training group ${ }^{18}$. Furthermore, Gosselin et al, demonstrated that body performance can be deteriorated by fatiguing on vibrating the neck muscles ${ }^{19}$. Moreover, Roijezon, et al reported conversely improved balance performance was reported after neck coordination exercises $^{20}$.

Some evidence suggests that conventional treatment of manual therapy and specific therapeutic exercise directed towards neuromuscular impairments are effective interventions for relieving neck pain $^{21}$ and dizziness symptoms ${ }^{22}$ and they improve cervical joint mobility and neck muscle performance ${ }^{23}$. However, these interventions are not specifically directed towards impaired cervical proprioception and balance. The effects of exercise and manual therapy on proprioception (joint reposition sense) and balance remain uncertain ${ }^{24}$

However, so far, all previous interventions were specifically targeting the neck muscle and postural control was assessed as the outcome measure. In contrast, additionally in this study, the exercise programs are individualized according to ongoing progress monitoring. It is expected that the findings of this trial will lead to improved clinical practice guidelines for persons with neck pain with impaired joint position sense and balance ${ }^{25}$.

The present data highlights the importance of training balance exercise may also beneficially alter sensorimotor function of neck muscles indicated by reduction in dizziness diagnostic tool scores. In summary, the effects of balance training on subjects with neck pain seem to be reduced when comparable to those reported after intervention.

Endurance training has also showed a statistically significant improvement, however lesser the significant than the motor control exercise group ${ }^{26}$. The study concludes that there seems to be evidence that endurance exercise are more beneficial in general exercise program in reducing neck pain and seems to be advantageous. ${ }^{27}$ The study concluded that samples in neck stabilization and postural correction showed better significance than stretch and strengthening exercise in reducing pain and disability and improving posture and breathing patterns $^{28}$. This systematic review maximum studies showed that there was some improvement in neck functional abilities and reduction in neck pain in the endurance training group ${ }^{29}$ The study concluded that the postural alignment achieved from schroth method is better than that achieved by yoga $\mathrm{a}^{30}$

\section{Conclusion}

The present study concludes that balance exercise were indeed efficient in reducing the neck pain, dizziness and in improving the functional activities of the subjects. Although, In the post treatment analysis, both the groups showed significant change in the outcome measures of VAS, tinetti balance assessment tool, dizziness scale, and patient specific functional scale, the group A has significant changes than the group B.

\section{Conflict of Interest: None}

Source of Funding: Nil, This is a self-funded study

Ethical Considerations: The manuscript is approved by the Institutional Review board of faculty of physiotherapy(IRB REF NO: IV C- 052/PHYSIO/ IRB/201-2019).

\section{Reference}

1. https://www.ncbi.nlm.nih.gov>articles.

2. Beinert $\mathrm{K}$, Taube $\mathrm{W}$. The effect of balance training on cervical sensorimotor function and neck pain. J Mot Behav. 2013;45(3):271-8.

3. Beer A, Treleaven J, Jull G. Can a functional postural exercise improve performance in the cranio-cervical flexion test?-a preliminary study. Man Ther. 2012;17(3):219-24.

4. Jull G, Falla D, Treleaven J, Hodges P, Vicenzino B. Retraining cervical joint position sense: the effect of two exercise regimes. J Orthop Res. 2007;25(3):404-12.

5. Treleaven J, Peterson G, Ludvigsson ML, Kammerlind AS, Peolsson A. Balance, dizziness and proprioception in patients with chronic whiplash associated disorders complaining of dizziness: a prospective randomized study comparing three exercise programs. Man Ther. 2016;22:122-30.

6. Kristjansson E, Dall'Alba P, Jull G. A study of five cervicocephalic relocation tests in three different subject groups. Clin Rehabil. 2003;17(7):768-74. 
7. Poole E, Treleaven J, Jull G. The influence of neck pain on balance and gait parameters in communitydwelling elders. Man Ther. 2008;13(4):317-24.

8. Jorgensen MB, Skotte JH, Holtermann A, Sjogaard G, Petersen NC, Sogaard K. Neck pain and postural balance among workers with high postural demands - a cross-sectional study. BMC Musculoskelet Disord. 2011. https://doi.org/10.1186/1471-247412-176.

9. Treleaven J. Sensorimotor disturbances in neck disorders affecting postural stability, head and eye movement control. Man Ther. 2008;13(1):2-11.

10. Field S, Treleaven J, Jull G. Standing balance: a comparison between idiopathic and whiplashinduced neck pain. Man Ther. 2008;13(3):183-91.

11. Jorgensen MB, Skotte JH, Holtermann A, Sjogaard G, Petersen NC, Sogaard K. Neck pain and postural balance among workers with high postural demands- a cross-sectional study. BMC Musculoskelet Disord. 2011;51(6):825-832.

12. Humphreys BK, Irgens P. The effect of a rehabilitation exercise program on head repositioning accuracy and reported levels of pain in chronic neck pain subjects. J Whiplash Relat Disord. 2002;1(1):99-112.

13. Jull G, Falla D, Treleaven J, Hodges P, Vicenzino B. Retraining cervical joint position sense: the effect of two exercise regimes. J Orthop Res. 2007;25(3):404-12.

14. Uthaikhup S, Assapun J, Watcharasaksilp K, Jull G. Effectiveness of physiotherapy for seniors with recurrent headaches associated with neck pain and dysfunction: a randomized controlled trial. Spine J. 2017;17(1):46-55.

15. Audette I, Dumas JP, Cote JN, De Serres SJ. Validity and between-day reliability of $\mathrm{B}$ the cervical range of motion (CROM) device. J Orthop Sports Phys Ther. 2010;40(5):318-23.

16. Uthaikhup S, Paungmali A, Pirunsan U. Validation of thai versions of the neck disability index and neck pain and disability scale in patients with neck pain. Spine (Phila Pa 1976). 2011;36(21):E141521.

17. Treleaven J, Murison R, Jull G, LowChoy N, Brauer $\mathrm{S}$. Is the method of signal analysis and test selection important for measuring standing balance in subjects with persistent whiplash? Gait Posture. 2005;21(4):395-402.
18. Revel M, Minguet M, Gregoy P, Vaillant J, Manuel JL. Changes in cervicocephalic kinesthesia after a proprioceptive rehabilitation program in patients with neck pain: a randomized controlled study. Arch Phys Med Rehabil1994;75:895-9.

19. Gosselin, G., Rassoulian, H., \& Brown, I. (2004). Effects of neck extensor muscles fatigue on balance. Clinical Biomechanics (Bristol, Avon), 19, doi:10.1016/j.clinbiomech. 2004.02.001S0268003304000312 [pii]473-479.

20. Roijezon, U., Bjorklund, M., Bergenheim, M., \& Djupsjobacka, M. (2008). A novel method for neck coordination exercise-a pilot study on persons with chronic non-specific neck pain. Journal of Neuroengineering and Rehabilitation, 5, 36. doi:1743-0003-5-36 [pii]10.1186/1743-0003-5-36.

21. Miller J, Gross A, D’Sylva J, Burnie SJ, Goldsmith $\mathrm{CH}$, Graham N, et al. Manual therapy and exercise for neck pain: a systematic review. Man Ther. 2010; 15(4):334-54.

22. Treleaven J, Peterson G, Ludvigsson ML, Kammerlind AS, Peolsson A. Balance, dizziness and proprioception in patients with chronic whiplash associated disorders complaining of dizziness: a prospective randomized study comparing three exercise programs. Man Ther. 2016;22:122-30.

23. Reid SA, Callister R, Katekar MG, Rivett DA. Effects of cervical spine manual therapy on range of motion, head repositioning, and balance in participants with cervicogenic dizziness: a randomized controlled trial. Arch Phys Med Rehabil. 2014;95(9):1603-12.

24. Uthaikhup S, Assapun J, Watcharasaksilp K, Jull G. Effectiveness of physiotherapy for seniors with recurrent headaches associated with neck pain and dysfunction: a randomized controlled trial. Spine J. 2017;17(1):46-55.

25. Jull G, Trott P, Potter H, Zito G, Niere K, Shirley D, et al. A randomized controlled trial of exercise and manipulative therapy for cervicogenic headache. Spine (Phila Pa 1976). 2002;27(17):1835-43.

26. Rajalaxmi.V., Jibi Paul, M. Manoj Abraham et al. Efficacy of Motor Control and Endurance Exercises in Neck Pain: A Pilot Study. Indian J Forensic Med Pathol. 2019;12(1):19-24.

27. V. Rajalaxmi, Jibi Paul, M. Manoj Abraham et al. Efficacy of Endurance vs Isometric Neck Exercise in Chronic Non - Specific Neck Pain: A RCT. Indian J Forensic Med Pathol. 2019;12(2):147-151 
28. Rajalaxmi. V, V. K. Madhu Ranjani, Jibi Paul, S. S. Subramanian, Bernard Ebenezer Cyrus, V. Pavithralochani, Efficacy of Neck Stabilization and Postural Correction Exercise on Pain, Posture, Disability, Respiratory Dysfuntions and Mental Status in Desk Job Workers - A Randomised Controlled Double Blinded Study, Research J. Pharm. and Tech. 12(5): May 2019

29. Rajalaxmi V, Jibi Paul, Manoj Abraham M, Sasirekha M, Nithya M, Efficacy of Endurance Exercise on Pain and Disability in Chronic Neck
Pain- A Systematic Review,Journal of Clinical and Diagnostic Research. 2018 Dec, Vol-12(12): YE05-YE13.

30. V. Rajalaxmi, Jiby Paul, M. Nithya, S. Chandra Lekha, B. Likitha, Effectiveness of Three Dimensional Approach of Schroth Method and Yoga on Pulmonary Function Test and Posture in Upper Crossed Syndrome With Neck Pain-A double blinded study, Research J. Pharm. and Tech. 11(5): May 2018 